Hydrol. Earth Syst. Sci. Discuss., 8, 5891-5915, 2011

www.hydrol-earth-syst-sci-discuss.net/8/5891/2011/

doi:10.5194/hessd-8-5891-2011

(c) Author(s) 2011. CC Attribution 3.0 License.
Hydrology and

\title{
Evaluation of the transferability of hydrological model parameters for simulations under changed climatic conditions
}

S. Bastola, C. Murphy, and J. Sweeney

Irish Climate Analysis and research Units, NUIM, Maynooth, Ireland

Received: 31 May 2011 - Accepted: 6 June 2011 - Published: 22 June 2011

Correspondence to: S. Bastola (satish.bastola@ nuim.ie)

Published by Copernicus Publications on behalf of the European Geosciences Union.

\section{HESSD}

$8,5891-5915,2011$

Evaluation of the transferability of hydrological model

S. Bastola et al.

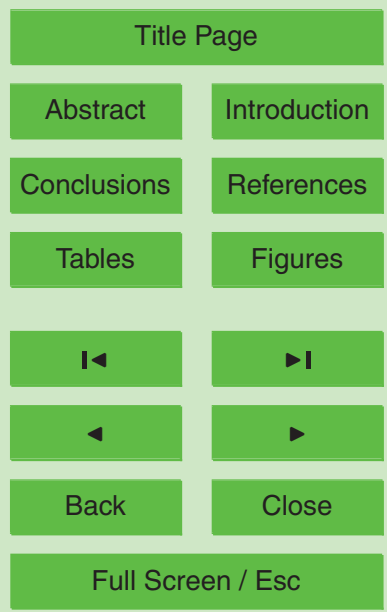

Printer-friendly Version

Interactive Discussion 


\section{Abstract}

Conceptual hydrological models are widely used for climate change impact assessment. The implicit assumption in most such work is that the parameters estimated from observations remain valid for future climatic conditions. This paper evaluates a simple 5 threshold based approach for testing this assumption, where a set of behavioural simulators are identified for different climatic conditions for the future simulation i.e. wet, average and dry conditions. These simulators were derived using three different data sets that are generated by sampling a block of one year of data without replacement from the observations such that they define the different climatic conditions. The simulators estimated from the wet climatic data set showed the tendency to underestimate flow when applied to dry data set and vice versa. However, the performances of the three sets of basin simulators on chronologically coherent data are identical to the simulators identified from a sufficiently long data series that contains both wet and dry climatic conditions. The results presented suggest that the issue of time invariance in the value of parameters has a minimal effect on the simulation if the change in precipitation is less than $10 \%$ of the data used for calibration.

\section{Introduction}

Conceptual Rainfall Runoff models (CRR) forced with regional climate change scenarios downscaled from Global Climate Models (GCMs) are widely employed to assess the impacts of climate change at the catchment scale (e.g., Bastola et al., 2011). CRR models, used for the quantification of different components of the hydrological cycle often require calibration against runoff obtained at the catchment outlet before they can be used for the purpose of making predictions, or simulating beyond the conditions of the calibration data. Calibrating parameters improves a model's goodness-of-fit for use, however, as the calibration exercise is set for a particular period with measured flow values, model parameters and performance are specific for that particular period.

\section{HESSD}

$8,5891-5915,2011$

\section{Evaluation of the transferability of hydrological model}

S. Bastola et al.

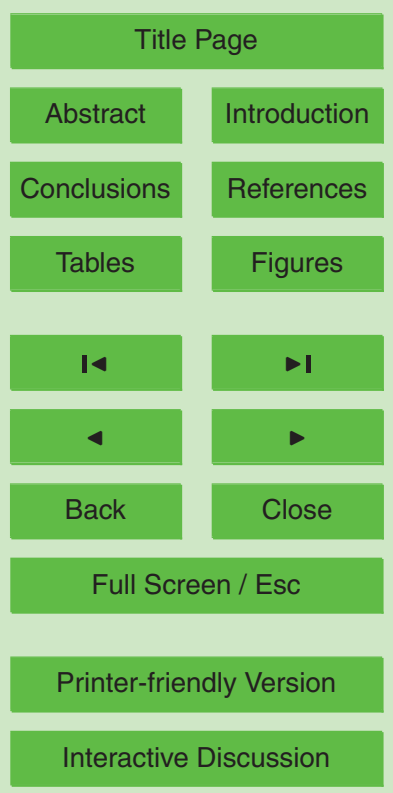


However, the same values are commonly used during subsequent periods for assessing the impact of climate change. Decreases in model performance have commonly been reported in the literature whenever calibrated parameters are used for periods and places other than those used for calibration (e.g., Merz and Bloschl, 2004). This is 5 because the environmental conditions of the catchments to which the parameters are applied may fall outside the range for which the model is conditioned and for which the parameters are valid.

In response to this problem the World Meteorological Organization (WMO) has long emphasized the testing of hydrological models on independent data. Klemes 10 (1986) proposed a hierarchical scheme for the systematic testing of hydrological simulation models before they are used for operational purposes. Similarly, Refsgaard and Knudssen (1996) proposed a theoretical framework for model validation, based on the method originally proposed by Klemes (1986). According to the author, differential split sample tests are required whenever such models are used to simulate flows in a given 15 gauged basin under conditions different from those corresponding to the available flow record. In this test, two periods with different values of the climate parameters of interest should be identified in the historic record, e.g. one with high average precipitation, the other with low. If the model is intended to simulate streamflow for a wet climate scenario then it should be calibrated on a dry segment of the historic record and validated on a wet segment. If it is intended to simulate flows for a dry climate scenario, the opposite should be done. In general, the model should demonstrate its ability to perform under the transition required: from drier to wetter conditions or the opposite.

However, historical data do not contain a long continuous period of different climatic conditions making it difficult for double split sample tests to be strictly adhered to. For 25 such cases, Klemes (1986) suggested the need for tests in a substitute basin where data availability allows the differential split-sample test. However, it is widely acknowledged in the literature that uncertainty in prediction arising from geographical transferability is always more severe than temporal transferability (Merz and Bloschl 2004). Alternatively, the application of hydrological models for conditions not observed during

\section{HESSD}

8, 5891-5915, 2011

\section{Evaluation of the transferability of hydrological model}

S. Bastola et al.

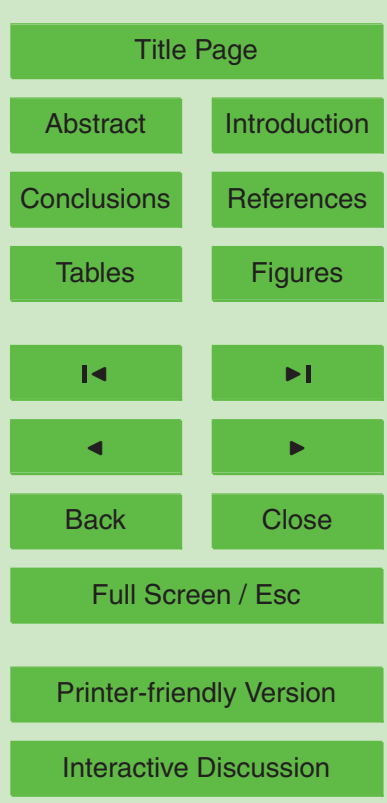

5893 
calibration can be done by adapting the parameters by functionally relating them with climatic parameters. However, such an approach is mainly hindered by the fact that parameters are not unique: a diverse set of possible parameter values can lead to similar model performances, a concept known as equifinality (Beven and Freer, 2001).

5 Much of the work on the application of hydrological models has previously focused on the prediction of un-gauged basin i.e., the spatial extrapolation of hydrological data using hydrological parameter regionalization (e.g., Wagener et al., 2004). The assumptions implicit in such applications are that catchments with similar characteristics show a similar hydrological behavior and thus can be modelled using similar model parame10 ters. However, only relatively few studies have looked into the temporal transferability of model parameters. Most of the applications of hydrological models to climate change impact studies assume that the parameters of models are time invariant (e.g., Bastola et al., 2011). Calibration of the model with a sufficiently long period of data that includes both dry and wet conditions has been long used as a strategy in studies. This 15 is based on the premises that if model parameters are calibrated against a long time series of historical data containing both wet and dry periods then these parameters can be assumed to be valid under future climates, with a greater degree of confidence (Arnell, 1993).

While evaluating the temporal transferability of parameters, Van der Linden and Woo 20 (2003) concluded that the use of non-updated parameters, divergent physical characteristics, or changed climatic conditions in a catchment model may yield unreliable results. Similarly, Halit et al. (2005) from their test on the temporal transferability of the parameters of the SLURP model recommend that the updated parameters should be used whenever a marked change occurs within the watershed. Hartmann and 25 Bárdossy (2005) have suggested a model parameterization scheme, where they used different climatic periods and timescale for calibration, to investigate the temporal transferability of hydrological models. Vaze et al. (2010) investigated whether or not the calibrated parameter values for rainfall-runoff models based on historical observed data can be used to reliably predict runoff responses to changes in future climate inputs.
HESSD

$8,5891-5915,2011$

\section{Evaluation of the transferability of hydrological model}

S. Bastola et al.

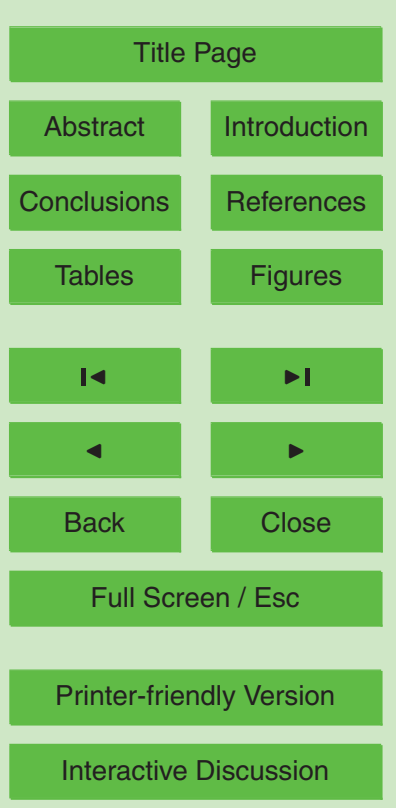

5894 
Their results, which involved four conceptual rainfall runoff models and 61 catchments located within Australia, indicate that the models, when calibrated using more than 20 yr of data, can generally be used for climate impact studies where the future mean annual rainfall is not more than 15 percent drier or 20 percent wetter than the mean 5 annual rainfall in the model calibration period. Furthermore, their insightful study also observed that it is generally more difficult for a model calibrated over a wet period to predict runoff over a dry period compared to a model calibrated over a dry period to predict runoff over a wet period.

In adding to this important and growing literature, this paper addresses the issue of 10 climatic transferability using a simple threshold based approach that relates behavioral sets of parameters to climatic conditions and subsequently uses these sets to adapt the parameters of hydrological models according to the climatic condition. Sets of behavioral simulators are identified for different climatic conditions using the GLUE methodology.

\section{Study region, data and models}

The method is demonstrated using two case study catchments in Ireland; the river Moy at Rahans $\left(1803 \mathrm{~km}^{2}\right)$, located on the western coast of Ireland and the Boyne at Slane $\left(2452 \mathrm{~km}^{2}\right)$ located on the east coast. Concerning the response and climate characteristics, the Moy basin is wetter and has a higher runoff coefficient than the 20 Boyne. Therefore, the Boyne basin can be considered to represent a dry basin whereas the Moy can be considered to represent a wet basin. Observed stream flow data was obtained from the Office of Public Works (available at http://www.opw.ie/hydro/), and observed precipitation and temperature data were obtained from Met Éireann, the Irish National Meteorological Service for the period from 1971-2000. In order to represent a future climate evolution a statistically downscaled climate scenario derived from HADCM3 for A2 emission scenario, downscaled by Fealy and Sweeney (2008) was used.

HESSD

$8,5891-5915,2011$

\section{Evaluation of the transferability of hydrological model}

S. Bastola et al.

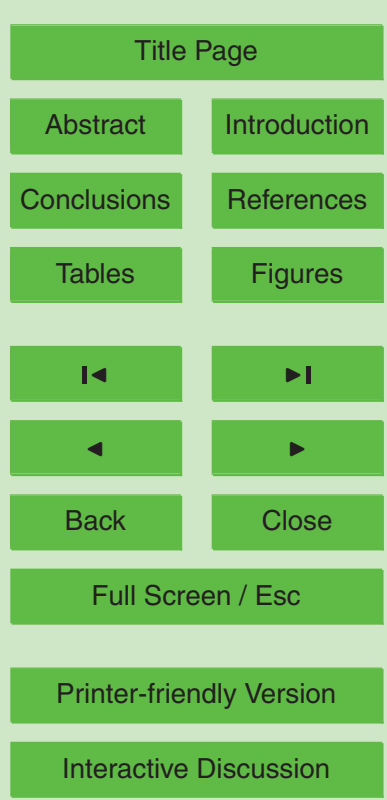


From among the large number of models that can be used for the purpose of modelling flow in catchments, we selected four conceptual rainfall runoff models; HYMOD (see Wagener et al., 2001), NAM (see Madsen 2000), TANK (Sugawara et al., 1995) and TOPMODEL (Beven et al., 1995). Each of these models vary in the way they conceptualize the key hydrological processes and in complexity, primarily related to the number of parameters requiring calibration. Among the four selected models, NAM and TANK describe the behavior of each component of the hydrological cycle at the catchments level by using a group of conceptual elements. Conversely, TOPMODEL and HYMOD are both variable contributing area models. In TOPMODEL the spatial variability is taken into account through indices derived from topography whereas in HYMOD, the spatial variability of hydrological response is modeled using a probability distribution function. All four models employ a single linear reservoir to model groundwater. The conceptual basis of these models enables the hydrological processes to realistically respond to changes in climatic input. The selected models have been applied in numerous applications and their potential for application to simulate flow under changed climate has been discussed previously. The models employed are independently developed by different researchers and organizations.

\section{Methodology}

The method for adapting the parameters of the hydrological models for future climate change impact studies (see Fig. 1) is as follows:

1. Select a number of structurally and/or parametrically different models.

2. Select three sets of calibration data representing periods where each data set define different climatic period's namely dry, average, and wet. These can be constructed by sampling the data in a block of one year from the observed time series, such that each set defines a different climatic condition based upon a
HESSD

$8,5891-5915,2011$

\section{Evaluation of the transferability of hydrological model}

S. Bastola et al.

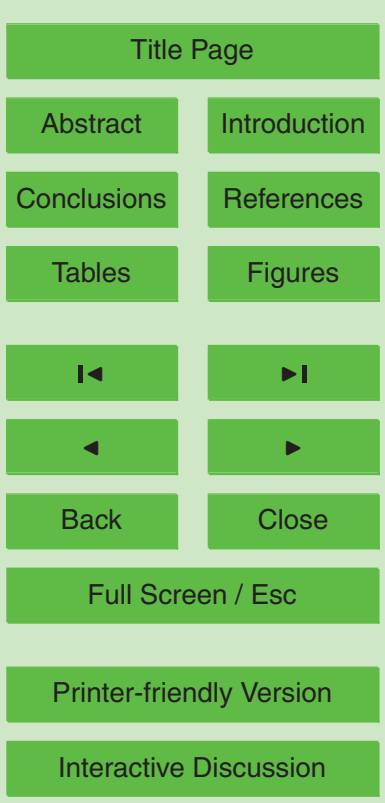


selected threshold. The three climatic periods used in the present application are as follows:

a. wet period: constitutes all years that have annual average rainfall greater than the threshold for a wet period ( $\mathrm{THw}$ )

b. average period: constitutes all years that have annual average rainfall in between the threshold for a wet and a dry period

c. dry period: constitutes all years that have annual average rainfall less than the threshold for a dry period (THd).

3. Use each of the three calibration sets independently to estimate behavioral basin simulators for selected models. Consequently, three calibration sets will result in three different sets of behavioural simulators namely, wet simulators, average simulators and dry simulators.

4. Adapt the behavioural simulators for simulation based on the value of annual average rainfall e.g., use wet behavioural simulators if annual average rainfall (AR) is greater than THw , dry if AR is smaller than THd and average if AR is in between THw and THd.

In order to evaluate the transferability of the hydrological model parameters using the above method, the simulations where parameters are adapted based on a selected threshold is compared with simulations from dry, average, wet and conventional simulators. The basin simulators identified from a sufficiently long period of data to cover both wet and dry periods are referred to as conventional simulators. The simulators identified from the wet, average and dry climatic conditions is referred as wet, average and dry basin simulators. Performance of each of these parameters, i.e., wet, average and dry were assessed against the sub periods other than those used during calibration. Furthermore, these parameters also need to be assessed for the chronological data as they were estimated from the resampled data.

HESSD

$8,5891-5915,2011$

Evaluation of the transferability of hydrological model

S. Bastola et al.

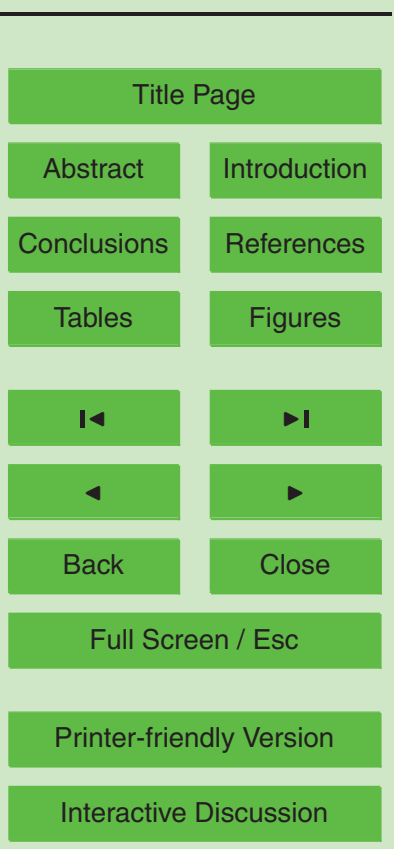


The GLUE method is used to identify the behavioural set of parameters or basin simulators and the quantity of uncertainty in the hydrological modelling. A major output of the GLUE method for assessing modelling uncertainty is the prediction interval at each time step, bounded by the lower prediction limit and the upper prediction limit, 5 and the median prediction. In order to assess the modelling result four objective criteria were employed, namely; the performance of the median prediction measured using of the Nash Sutcliffe efficiency criteria and overall volume error, an index that reflects the capability of the prediction intervals to capture the observed values (count efficiency), and the average width delete of the prediction interval.

\section{Results}

Four hydrological models namely, HYMOD, NAM, TOPMODEL and TANK were calibrated and validated based on the observed data set that extends from 1971 to 2000. The behavioural sets of parameters calibrated from this period were taken from Bastola et al. (2011). The period used by the authors for calibration is sufficiently long to cover both wet and dry periods, i.e. the 1970 s is a relatively dry decade whereas the 1980 s is relatively wet. For the identification of the basin simulators, the GLUE methodology is used where the Nash Sutcliffe Efficiency Criteria (NSE) is used for the evaluation of parameters, and the parameter domain is defined using minimum and maximum values through a uniform distribution.

20 Furthermore, three different sets of behavioral basin simulators were derived for each of the three calibration data sets (see Methodology). The three different data sets that define dry, average and wet climatic conditions, constructed from the observations which extends from 1971-2000, were used for the identification of dry, average and wet basin simulators. For this, the GLUE methodology was again used. The characteristics of the rainfall data set i.e., probability that a wet day follows a wet day (Pww), the probability that a dry day follows a dry day (Pdd), and the average rainfall intensity (Pav), used for calibration and evaluation of climatic transferability is summarized in Table 1. The percentage change in annual average precipitation for intermittent dry and 5898
HESSD

8, 5891-5915, 2011

\section{Evaluation of the transferability of hydrological model}

S. Bastola et al.

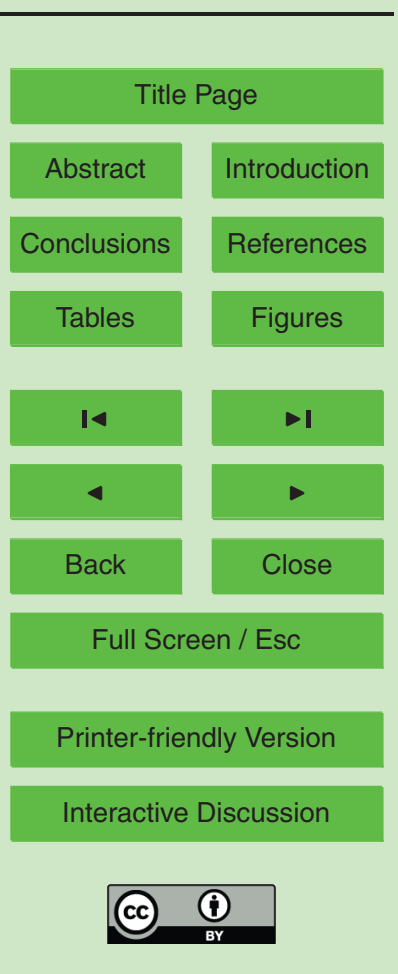


wet data sets is nearly $20 \%(17 \%)$ when moving from the dry calibration to wet period for the Boyne (Moy) basins. The percentage change in annual average precipitation is nearly $12 \%$ (7\%) when moving from 1970s (dry decade) to 1980s (wet decade) for the Boyne (Moy) basin.

$5 \quad$ Figure 2 shows the performance of the selected models in two dimension objective spaces (NSE and volume error) when parameters calibrated from dry (wet) period (dry and wet basin simulators) are evaluated on both wet and dry periods. Though the loss in NSE is small, it varied when moving from one climatic period to the other. Moreover, the change in volume error in stream flow, when moving from one period to the other, 10 is markedly higher than NSE. The wet (dry) basin simulators show the tendency to produce less (more) runoff in dry (wet) periods. In addition, the volume error in the streamflow is lower for the wet period than for the dry period for all models and both basins.

Among the models used, TANK and TOPMODEL showed the tendency to overesti15 mate flow, in the two basin considered in this study, whereas opposite is observed for HYMOD and NAM model. The HYMOD uses linear stores to route the flow, whereas NAM uses a linear store for soil moisture storage that controls the different components of runoff. However, TANK uses nonlinear stores and TOPMODEL uses an exponential store.

20 In order to improve the performance of hydrological models, a number of modifications can be made to the model structures. As the most notable differences in models used in this study are the use of linear and nonlinear storages for surface runoff generation, we revised the storage outflow relationship used in NAM and HYMOD if such revision addresses the discrepancies observed among models.

25 In the HYMOD model, the routing component consists of a series of three linear reservoirs for quick flow and one linear reservoir for slow flow. In this study, two nonlinear coefficients i.e., one for quick flow and the other for slow flow, are introduced to represent the relationship between storage and outflow using a nonlinear function (See Eq. 1).

\section{HESSD}

$8,5891-5915,2011$

\section{Evaluation of the transferability of hydrological model}

S. Bastola et al.

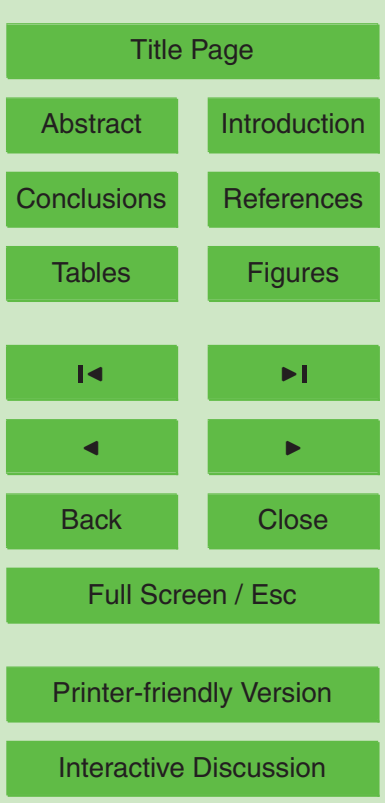


This modification adds two additional parameters to the original HYMOD (HYMOD_5) and is referred to as HYMOD_7, where 7 represent the number of parameters. Similarly, in the NAM model, the surface runoff and infiltration are controlled by a linear 5 store called lower soil moisture storage. A nonlinear coefficient is added so that both the surface runoff and infiltration are a nonlinear function of the storage in the lower soil moisture storage tank. These modifications add one parameter to the original NAM model (NAM_9) and is referred to as NAM_10. Figure 3 shows the performance of original and modified model structure for NAM and HYMOD for the Moy river catchment. It is apparent from the figure that the use of the nonlinear store in TOPMODEL and TANK is likely to be the reason for overestimation of flow compared to HYMOD and NAM. As this study is a part of the work that focus on the simulation of a role of hydrological model selection uncertainty in the future simulation of climate, the original four version of the model were only investigated for the transferability of the parameter of hydrological model for the simulation of flow for changed climate.

As the periods used for the calibration of the model are not continuous in time, the estimated basin simulators were also used for simulation with the chronological data. For this purpose, the 1970s decade and the 1980s decade, which represent dry and wet decades respectively were used. The performances for two climatic periods, namely dry (1970s) and wet (1980s) are summarized in Fig. 4. In general, the spread in points in objective space (i.e., NSE and Volume error) is smaller for the wet period than for the dry period for all the selected models. Moreover, the seasonal flow for both the dry and wet period is shown in Fig. 5 for the Boyne and Moy basins using dry and wet behavioural simulators.

25 For the HYMOD model, some of the wet basin simulators resulted in flow that is markedly lower than the same produced with dry simulators. For NAM and TANK, points in objective space for both wet and dry simulators are identical. However, for TOPMODEL, the performances of wet simulators are marginally better than dry simulators for both the dry and wet period.

\section{HESSD}

8, 5891-5915, 2011

\section{Evaluation of the transferability of hydrological model}

S. Bastola et al.

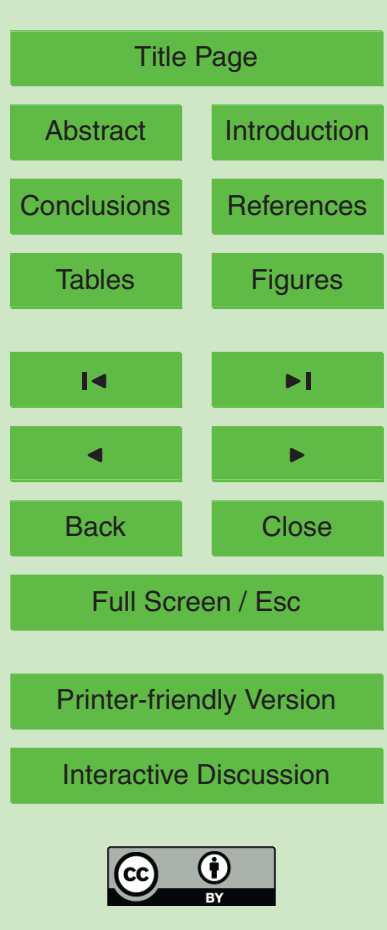


The transferability of parameters for the future climate is evaluated using a future climate scenario as input to each model and comparing the simulation with and without adapting the parameters. For the adaptation of parameters to climate, the basin simulators were selected from among wet, average and dry basin simulators depending 5 upon the average rainfall and the chosen threshold for wet and dry conditions. Figure 6 shows the performance of conventional parameters, which are assumed to remain constant in time, and the adapted parameters. The performance with un-updated parameters are scattered more than with the updated parameters. Figure 7 shows the seasonal prediction interval with and without parameter adaptation. The prediction o interval and median prediction are significantly similar in both figures.

Figure 8 shows the Euclidian norm, defined as the average distance from each point in objective space (Figs. 4 and 6 ) to the point of ideal performance (NSE $=1$ and Volume error $=0$ ). The results show that different models respond differently to wet, dry, adapted and un-adapted basin simulators. TOPMODEL showed the greatest sensitivity to different parameter set compared to the other models. Moreover, simulations from NAM and HYMOD were found to be more attractive for the dry period, whereas TANK and TOPMODEL performances are more attractive for wet period. In most instances, the differences among models are minimal for adapted and un-adapted parameter sets. Moreover, the differences in the response of models to dry, average, wet, adapted and un-adapted basin simulators are more visible for the wet period.

Table 2 summaries the results from the simulations with conventional, dry, average, wet and adapted parameters in terms of NSE, volume error, Count Efficiency, and the average width of the prediction interval. The performance of each of these simulators in terms of the selected objective criteria is identical and suggests that for the range of climatic conditions (i.e. $12 \%$ for Boyne and $7 \%$ for Moy change in annual average rainfall) used for model calibration, the issue of parameter invariance/variance has minimal effect on the simulation for the four selected conceptual models.

From among regional climate scenarios available for Ireland (see Fealy and Sweeney 2008), the average annual rainfall for the driest regional scenario for the 2080s (i.e.,
HESSD

$8,5891-5915,2011$

\section{Evaluation of the transferability of hydrological model}

S. Bastola et al.

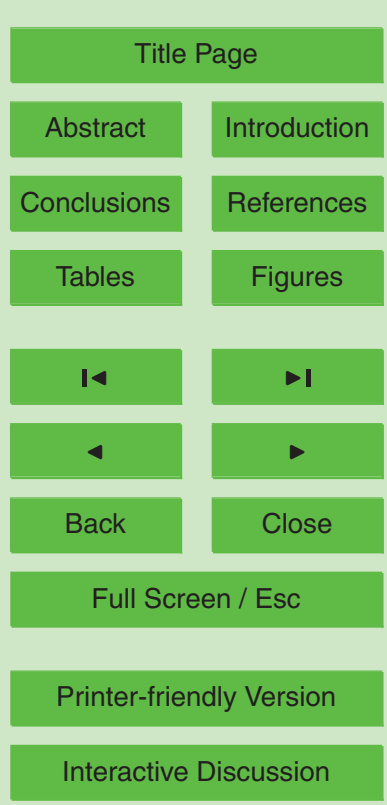


$2071-2100$ ) is $10 \%$ less than that of the period $1971-1990$ and for the wettest regional scenarios are $6 \%$ higher than the observed average for the Boyne and $4 \%$ less for the Moy basin. The annual average rainfall for the data used for dry calibration is $8 \%$ and $10 \%$ less than that of control period for the Boyne and Moy respectively. Sim5 ilarly, the average rainfall for the data used for wet calibration is $10 \%$ and $6 \%$ more than that of the control period. The differences in regional climatic conditions compared to the observed data are well within the range of dry and wet climatic conditions that were used for the calibration of model parameters. Using a regional climate scenario generated using statistical downscaling from the HADCM3 global climate model 10 a future hydrological response is defined. Figure 9 shows the seasonal flow for both the Boyne and Moy with and without adaptation of the parameters. Results are identical thereby indicating that when the future rainfall does not change more than $10 \%$ from the present condition, the parameters calibrated from a long time period still hold acceptable for the future simulation.

\section{Conclusion}

If a model is to be used for developing decisions about management options under future climatic conditions, its parameters and process descriptions should be transferable. However, the uncertainty in model parameters thwarts the successful construction of relationships between model parameters and climatic attributes and consequently hinders the transferability of parameters to future conditions. This study proposes a simple threshold based approach for assessing the climatic transferability of parameters of hydrological models. The evaluation reveals that parameters trained under dry conditions tend to underestimate flow when used to simulate wet conditions. In this application the wet dataset had $20 \%$ more rainfall than the dry period and vice versa. However, the use of dry and wet simulators on chronologically consistent data, i.e., 1970 s (dry) and 1980s (wet), shows that performance in objective space is identical to the conventional simulators. For these two periods, the percentage change in annual
HESSD

$8,5891-5915,2011$

\section{Evaluation of the transferability of hydrological model}

S. Bastola et al.

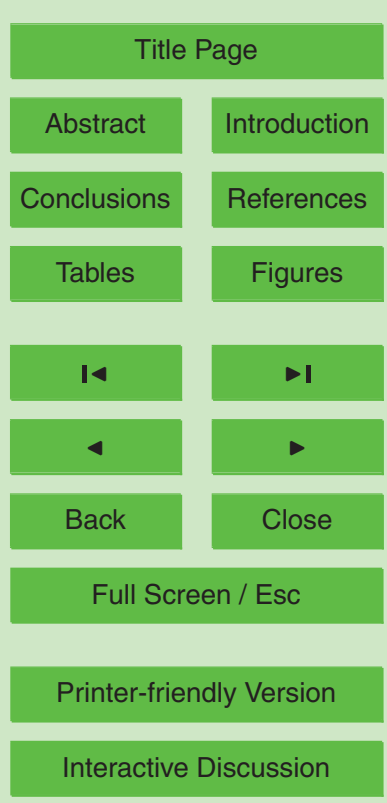


average precipitation is nearly $12 \%(7 \%)$ for Boyne (Moy) basins. Furthermore, for the period from 1970 to 1990 the implementation of a routine for the continuous adaptation of parameters based on annual average rainfall resulted in performances that are almost identical to the conventional simulators. This simple example thus shows 5 that for the basins and the models used in this study, the assumption that parameters do not vary in time still holds true if the change in annual precipitation is less than $10 \%$.

Acknowledgements. This work received financial support from Science Foundation Ireland's Research Frontiers Programme under the project title "Quantifying the cascade of uncertainty in climate change impacts for the water sector".

\section{References}

Arnell, N. W: Hydrology and climate change, in: The rivers handbook, edited by: Calow, P. and Petts, G. E., 2, 173-185, 1993.

Bastola, S., Murphy, C., and Sweeney, J.: The role of hydrological modelling uncertainties in climate change impact assessments of Irish river catchments, Adv, Water Resour., 34(5), 15 562-576, doi:10.1016/j.advwatres.2011.01.008, 2011.

Beven, K., Lamb, R., Quinn, P., Romanowicz, R., and Freer, J.: TOPMODEL, in: Computer Models of Watershed Hydrology, edited by: Singh, V. P., Water Resources Publications, Highlands Ranch, CO, 627-668, 1995.

Beven, K. and Freer, J.: Equifinality, data assimilation, and data uncertainty estimation in mechanistic modelling of complex environmental systems using the GLUE methodology, J. Hydrol., 249, 11-29, 2001.

Fealy, R. and Sweeney, J.: Climate scenarios for Ireland, in: Climate Change: Refining the Impacts. Environmental Protection Agency, Johnstown Castle, edited by: Sweeney, J., Wexford, Government Publications, 5-38, 2008.

25 Halit, A., Alper, S. A., and Ahmet, O.: The temporal transferability of calibrated parameters of a hydrological model, Ecol. Model., 195(3-4), 2006.

Hartmann, G. and Bárdossy, A.: Investigation of the transferability of hydrological models and a method to improve model calibration, Adv. Geosci., 5, 83-87, 2005
HESSD

$8,5891-5915,2011$

Evaluation of the transferability of hydrological model

S. Bastola et al.

Title Page

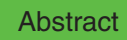

Introduction

Conclusions

References

Tables

Figures

14

$\rightarrow$

4

Back

Close

Full Screen / Esc

Printer-friendly Version

Interactive Discussion 
Klemeš, V.: Operational testing of hydrologic simulation models, Hydrolog. Sci. J., 31(1), 13-24, 1986.

Van Der Linden, S. and Woo, M.: Transferability of hydrological model parameters between basins in data-sparse areas, subarctic Canada, J. Hydrol., 270, 182-194, 2003.

5 Madsen, H.: Automatic calibration of a conceptual rainfall-runoff model using multiple objectives, J. Hydrol., 235, 276-288, 2000.

Merz, R. and Blöschl, G.: Regionalisation of catchment model parameters, J. Hydrol., 287, 95-123, 2004.

Refsgaard, J. C. and Knudsen, J.: Operational validation and intercomparision of different types of hydrological models, Water. Resour. Res., 32(7), 2189-2202, 1996.

Sugawara, M.: Tank model, in: Computer models of watershed hydrology, edited by: Singh, V. P., Water Resources Publication, Littleton, Co, 165-214, 1995.

Vaze, J., Post, D. A., Chiew, F. H. S., Peraud, J. M., Viney, N., and Teng, J.: Climate nonstationarity - Validity of calibrated rainfall-runoff models for use in climate change studies, J.

15 Hydrol., 394, 447-457, doi:10.1016/j.jhydrol.2010.09.018, 2010.

Wagener, T., Wheater, H. S., and Gupta, H. V.: Rainfall-Runoff Modelling in Gauged and Ungauged Catchments, Imperial College Press, London, 2004.

Wagener, T., Boyle, D. P., Lees, M. J., Wheater, H. S., Gupta, H. V., and Sorooshian, S.: A framework for development and application of hydrological models, Hydrol. Earth Syst. Sci., 5, 13-26, doi:10.5194/hess-5-13-2001, 2001.

\section{HESSD}

8, 5891-5915, 2011

\section{Evaluation of the transferability of hydrological model}

S. Bastola et al.

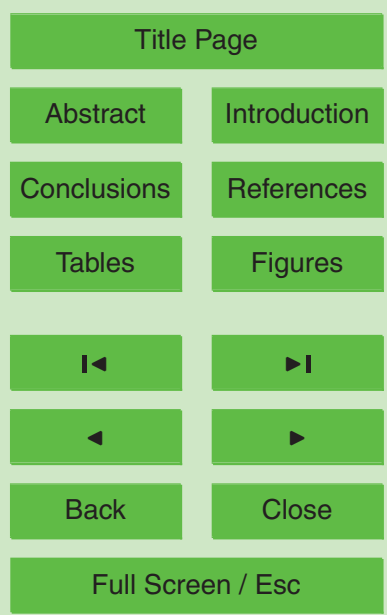

Printer-friendly Version

Interactive Discussion 


\section{HESSD}

$8,5891-5915,2011$

\section{Evaluation of the transferability of \\ hydrological model}

Table 1. Characteristics of rainfall used for calibration and validation of hydrological model parameters. Pww is the probability of wet day following wet day, Pdd is the probability of dry day following dry day, and Pav is the annual average rainfall intensity ( $\mathrm{mm} \mathrm{day}^{-1}$ ).

\begin{tabular}{|c|c|c|c|c|c|c|c|c|}
\hline \multirow[t]{3}{*}{ SN } & \multirow{3}{*}{ Period } & \multicolumn{3}{|c|}{ Boyne } & \multicolumn{3}{|c|}{ Moy } & \multirow[t]{3}{*}{ Remarks } \\
\hline & & \multicolumn{3}{|c|}{ Rainfall (Cal) } & \multicolumn{3}{|c|}{ Rainfall (Cal) } & \\
\hline & & Pww & PDD & Pav & Pww & PDD & Pav & \\
\hline 1 & $1971-1990$ & 0.58 & 0.70 & 2.50 & 0.66 & 0.67 & 3.26 & Chronological \\
\hline 2 & Dry Period & 0.57 & 0.72 & 2.30 & 0.67 & 0.65 & 2.94 & Intermittent \\
\hline 3 & Ave Period & 0.58 & 0.70 & 2.53 & 0.68 & 0.65 & 3.39 & Intermittent \\
\hline 4 & Wet period & 0.61 & 0.68 & 2.75 & 0.67 & 0.65 & 3.44 & Intermittent \\
\hline 5 & 1970s & 0.56 & 0.70 & 2.37 & 0.65 & 0.68 & 3.27 & Chronological \\
\hline 6 & $1980 \mathrm{~s}$ & 0.60 & 0.69 & 2.66 & 0.66 & 0.67 & 3.16 & Chronological \\
\hline 7 & $1990 \mathrm{~s}$ & 0.60 & 0.72 & 2.59 & 0.67 & 0.68 & 3.39 & Chronological \\
\hline
\end{tabular}

S. Bastola et al.

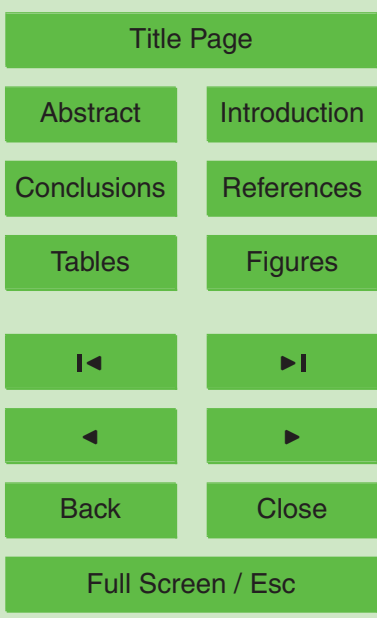

Printer-friendly Version

Interactive Discussion 


\section{HESSD}

$8,5891-5915,2011$

Table 2. Summary of model simulation for Boyne and Moy Basin using four hydrological models and for six different schemes using generalized likelihood uncertainty estimation method.

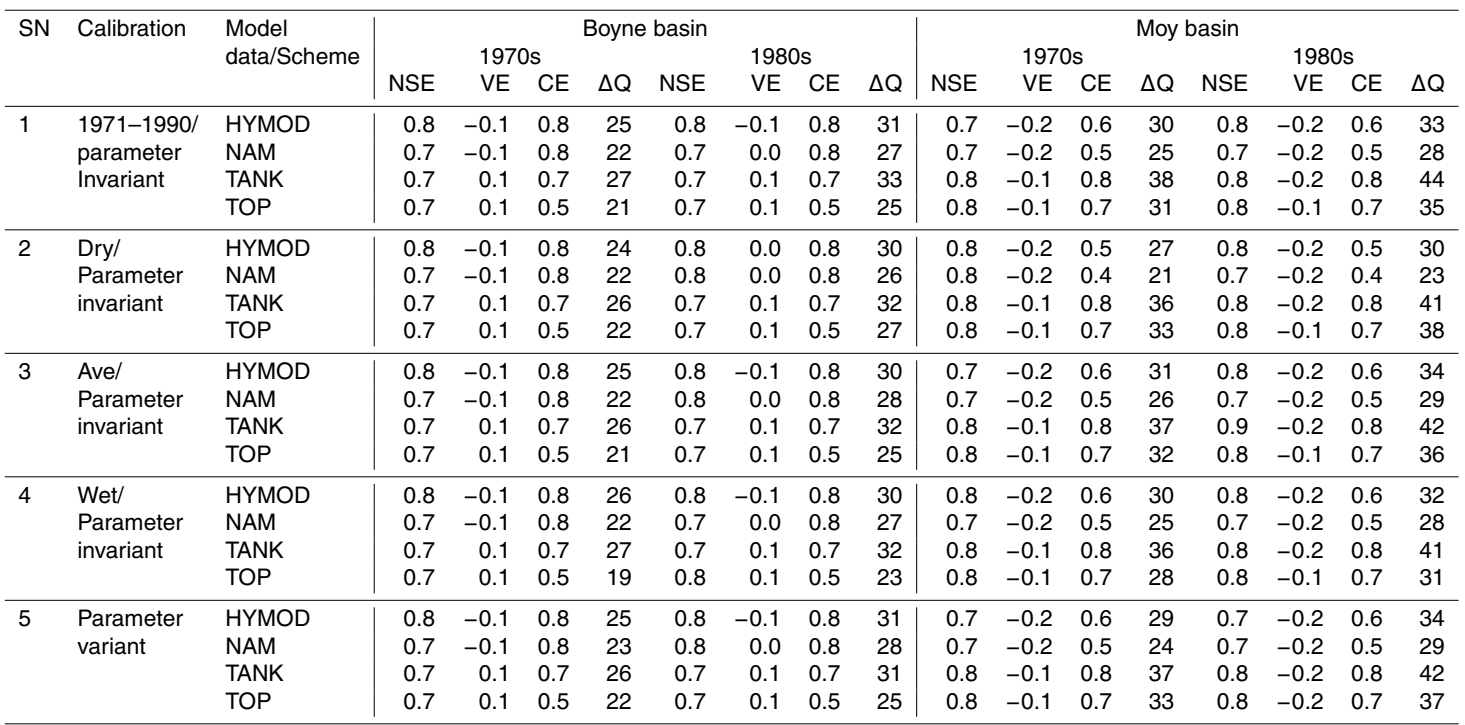

\section{Evaluation of the transferability of hydrological model}

S. Bastola et al.

\section{Title Page}

\section{Abstract}

Introduction

Conclusions

References

Tables

Figures

14

4

Back

Close

\section{Full Screen / Esc}

Printer-friendly Version

Interactive Discussion 


\section{HESSD}

$8,5891-5915,2011$

\section{Evaluation of the transferability of hydrological model}
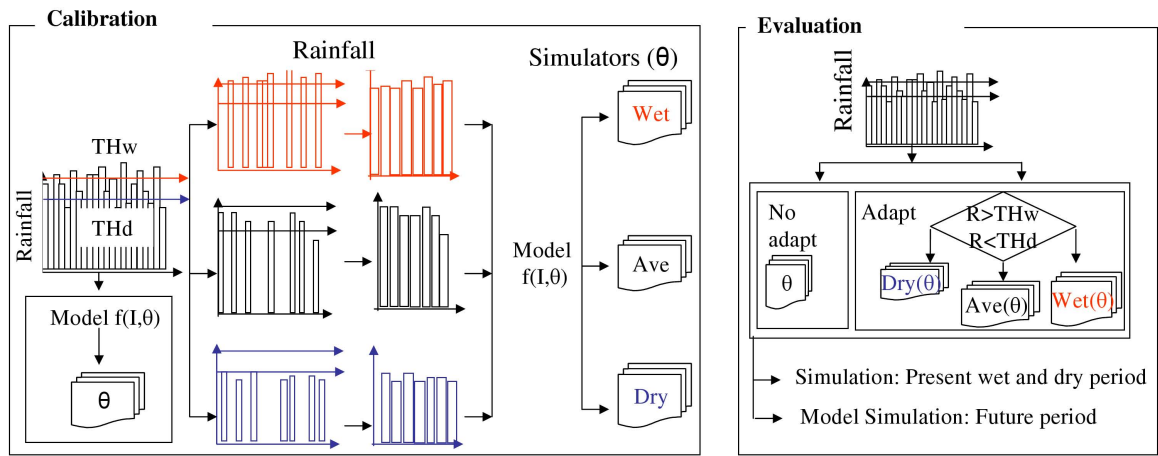

S. Bastola et al.

Fig. 1. Methodology for evaluating the climatic transferability of rainfall runoff model parameters.

Title Page

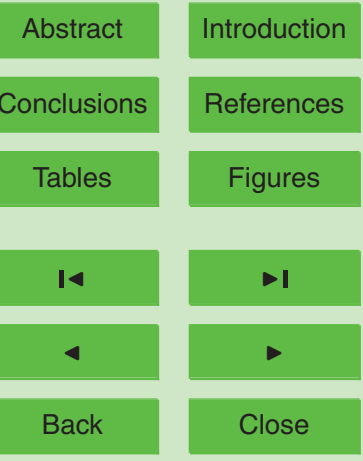

Full Screen / Esc

Printer-friendly Version

Interactive Discussion 


\section{HESSD}

$8,5891-5915,2011$

\section{Evaluation of the transferability of hydrological model}

S. Bastola et al.

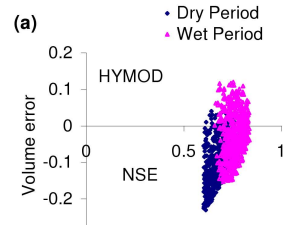

$-0.3$
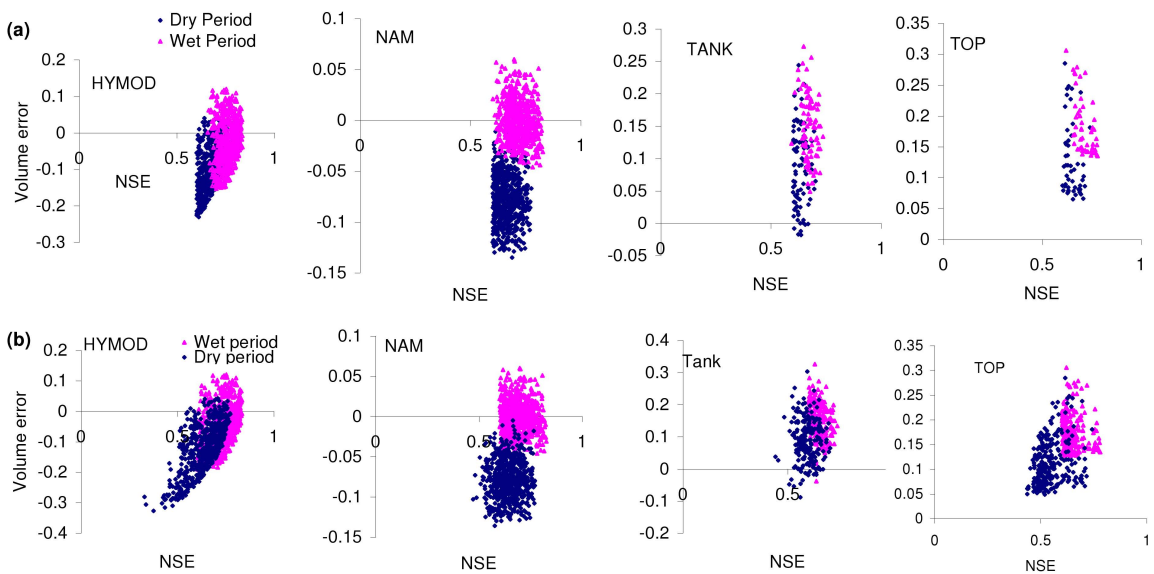

Fig. 2. Model performance in two dimension objective space for parameter sets identified for (a) dry period (b) wet period. The result includes simulation of the Boyne basin using HYMOD, NAM, TANK and TOP model.

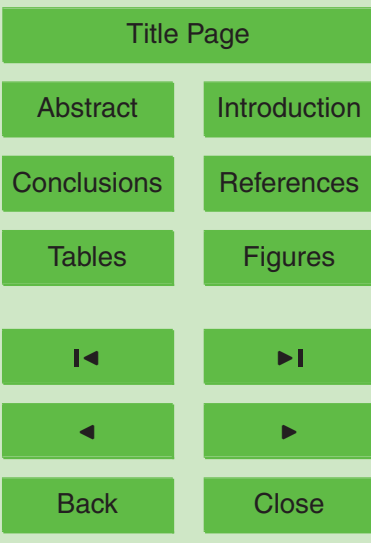

Full Screen / Esc

Printer-friendly Version

Interactive Discussion 
HESSD

$8,5891-5915,2011$

\section{Evaluation of the transferability of hydrological model}

S. Bastola et al.

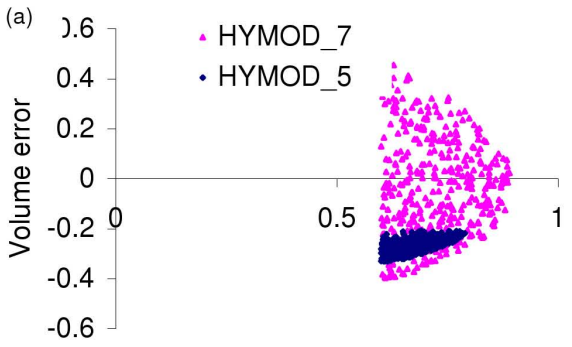

NSE
Fig. 3. Comparison of the performance of revised and unrevised models (a) HYMOD (b) NAM model.

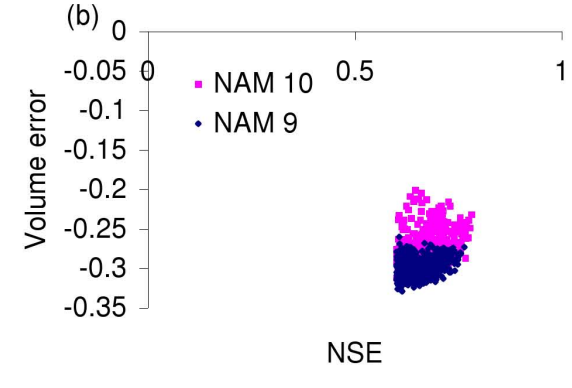

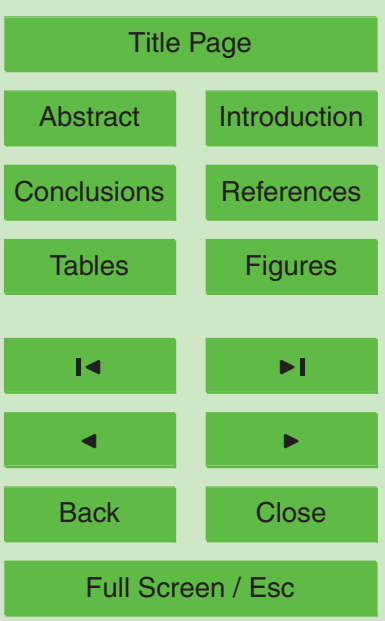

Printer-friendly Version

Interactive Discussion 


\section{HESSD}

8, 5891-5915, 2011

\section{Evaluation of the transferability of hydrological model}

S. Bastola et al.

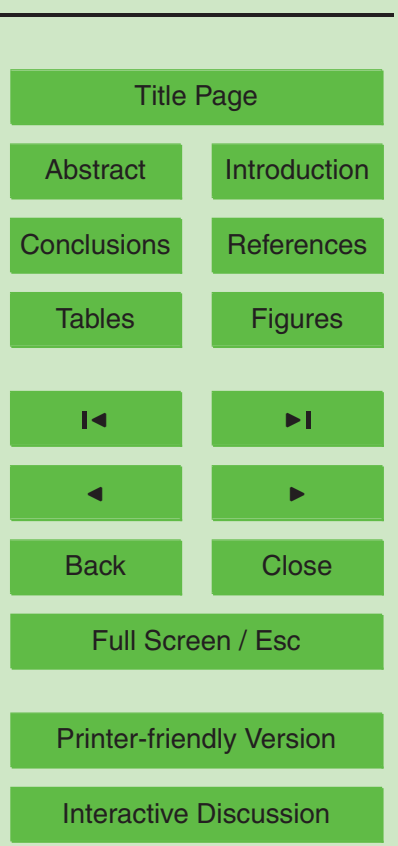

Fig. 4. Performance of dry and wet basin simulators for the Boyne basin (a) 1970s (Dry decade) and (b) 1980s (Wet decade).
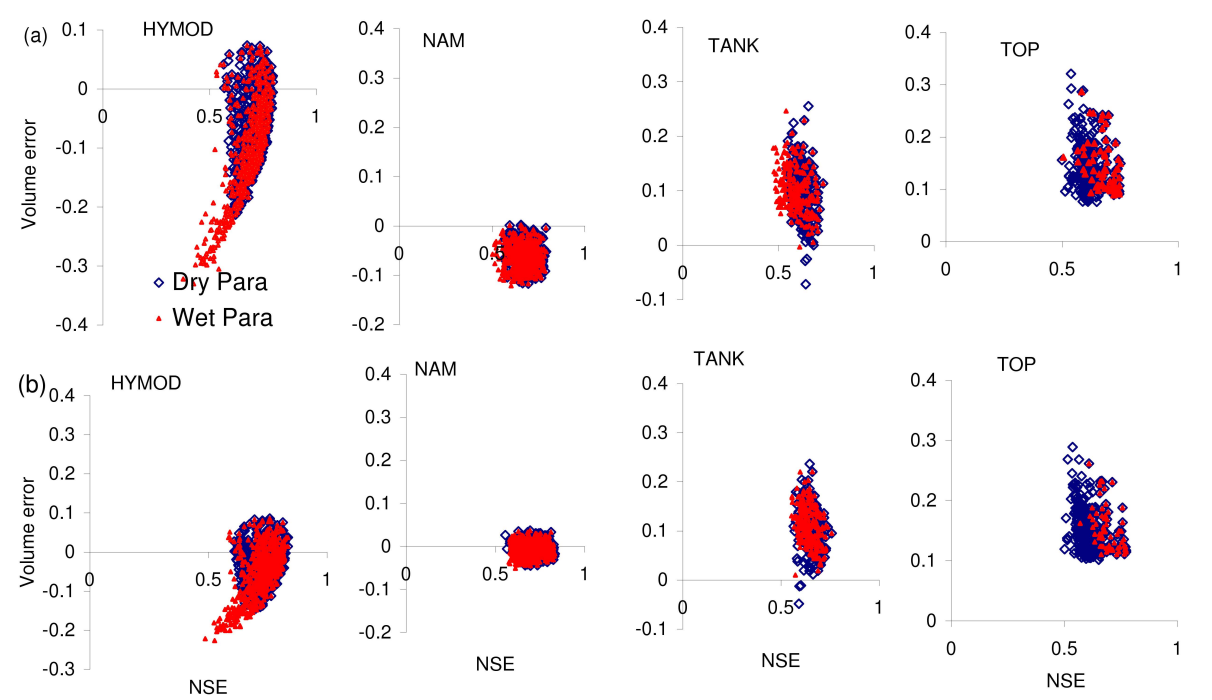


\section{HESSD}

$8,5891-5915,2011$

(a)
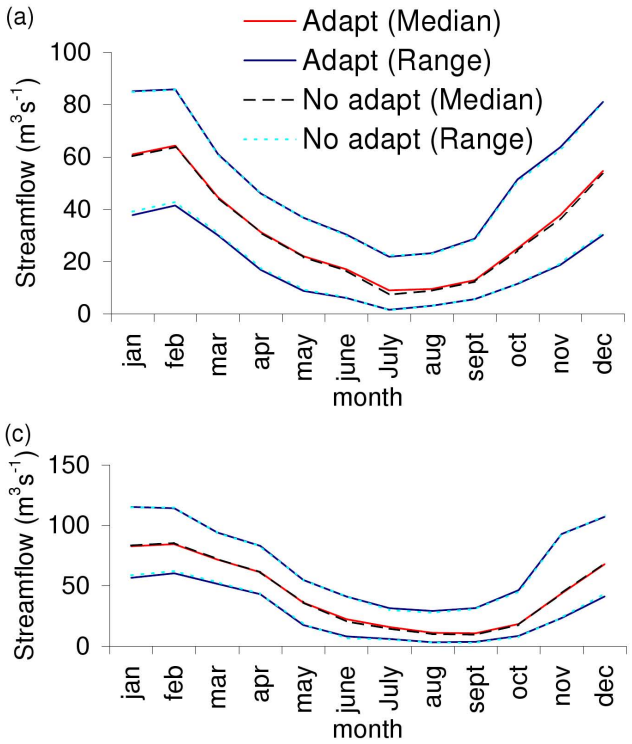

(b)
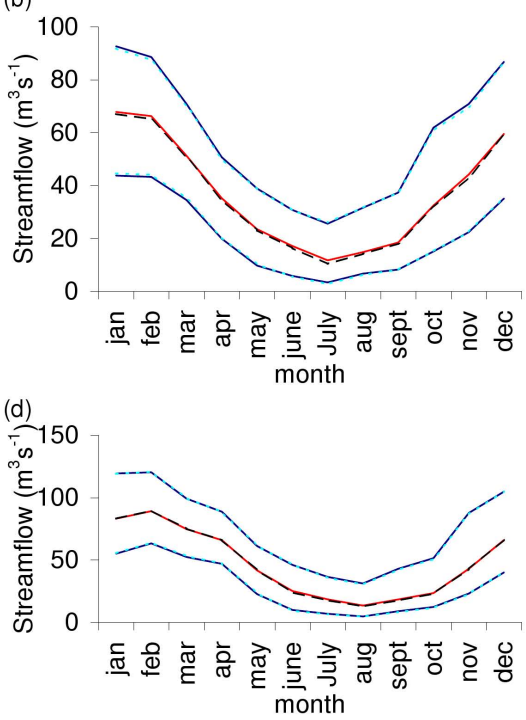

Fig. 5. Model simulated seasonal prediction intervals for the period 1970s (Dry decade) and 1980s (wet decade) with and without adapting basin simulators (a and $\mathbf{b}$ ) Boyne river basin, (c and d) Moy river basin.

\section{Evaluation of the transferability of hydrological model}

S. Bastola et al.

\section{Title Page}

Abstract

Introduction

Conclusions

References

Tables

Figures

14

4

\section{Back}

Close

\section{Full Screen / Esc}

Printer-friendly Version

Interactive Discussion 


\section{HESSD}

$8,5891-5915,2011$

\section{Evaluation of the transferability of \\ hydrological model}
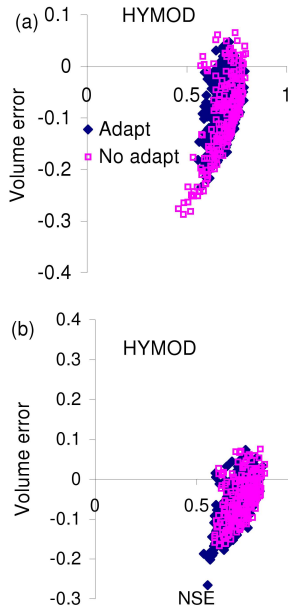

NAM

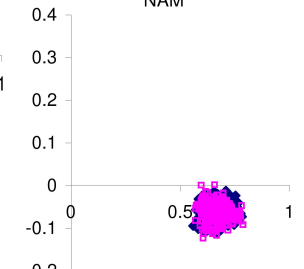

$0.4 \quad$ NAM

0.3

0.2

0.1

$0.1^{0}$

$-0.2$

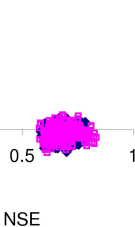

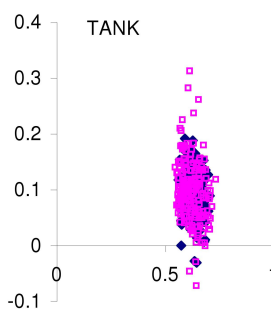
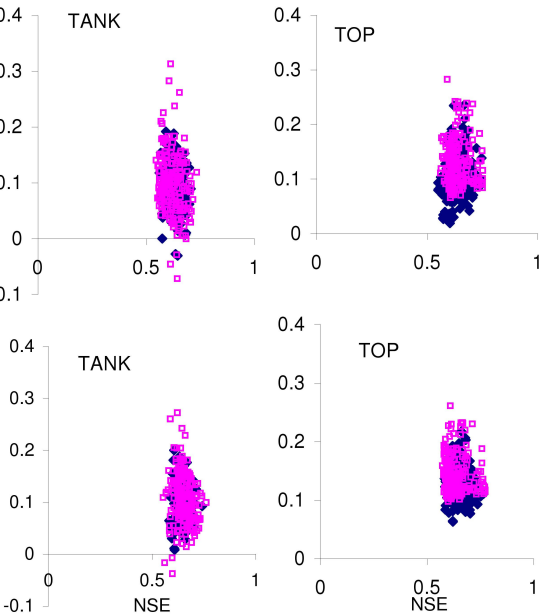

TOP

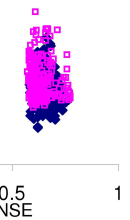

Fig. 6. Performance of basin simulators for Boyne river catchment adapted based on annual average rainfall, and the basin simulators obtained from long period of data containing wet and dry period (No adapt) (a) 1970s (Dry decade) (b) 1980s (Wet decade).
S. Bastola et al.

\section{Title Page}

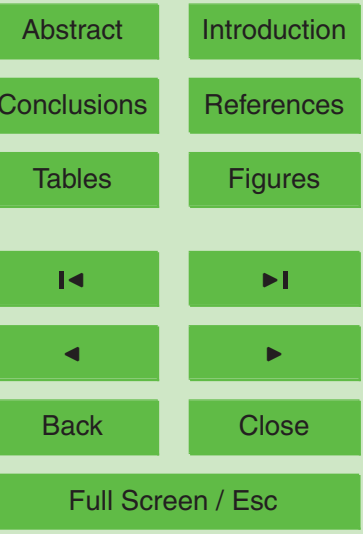

Printer-friendly Version

Interactive Discussion 


\section{HESSD}

$8,5891-5915,2011$

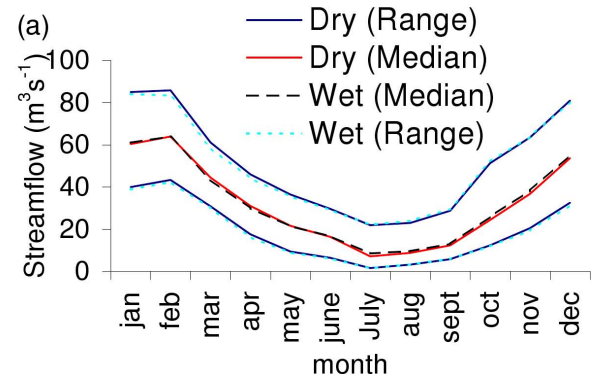

(C)

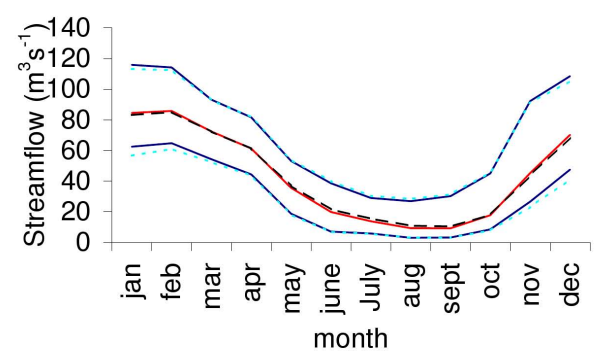

(b)

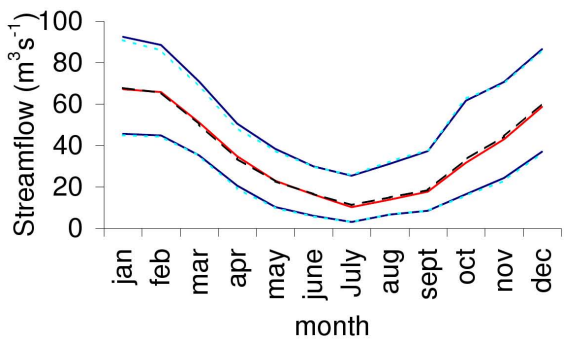

(d)

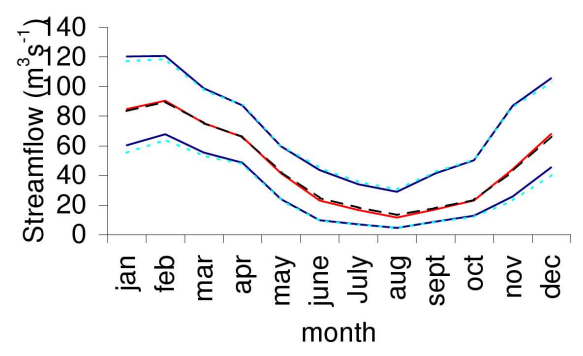

Fig. 7. Seasonal prediction intervals for the period from 1971-2099 with and without adapting basin simulators ( $\mathbf{a}$ and $\mathbf{b}$ ) Boyne river basin, (c and $\mathbf{d})$ Moy river basin.

\section{Evaluation of the transferability of hydrological model}

S. Bastola et al.

\section{Title Page}

Abstract Introduction

Conclusions

References

Tables

Figures

14

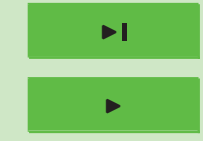

Back

Close

\section{Full Screen / Esc}

Printer-friendly Version

Interactive Discussion 

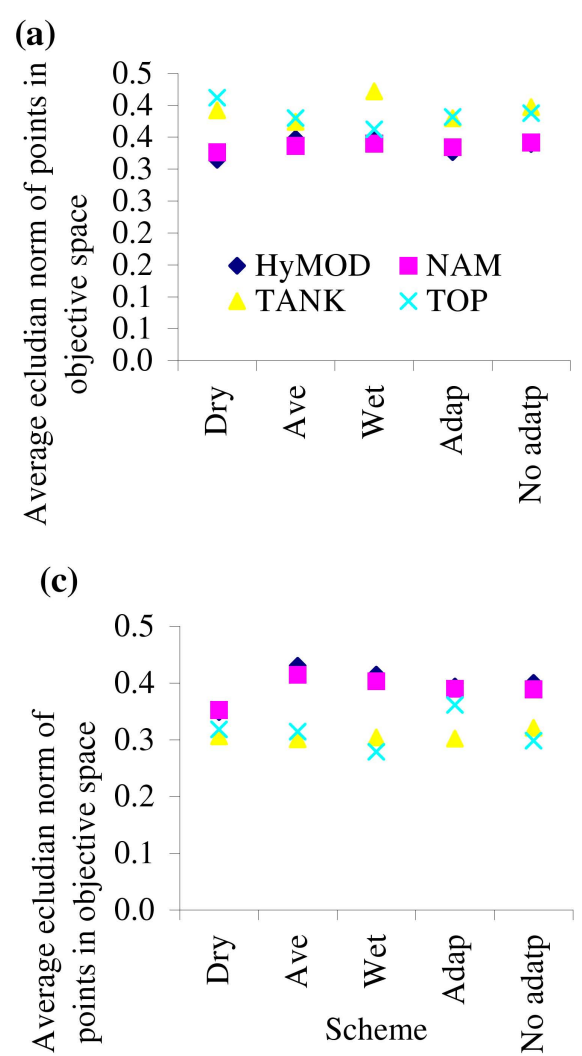

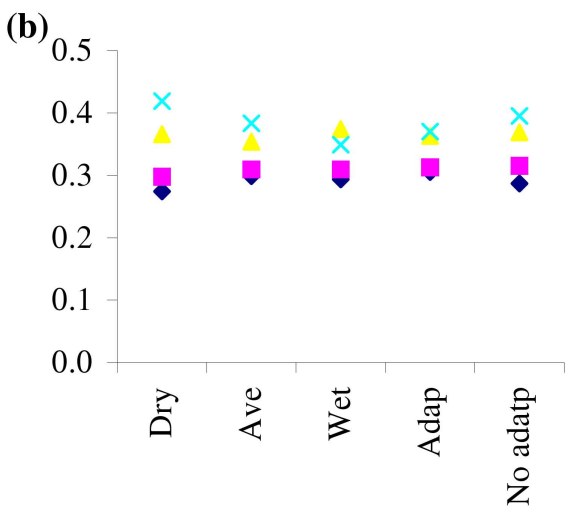

(d)

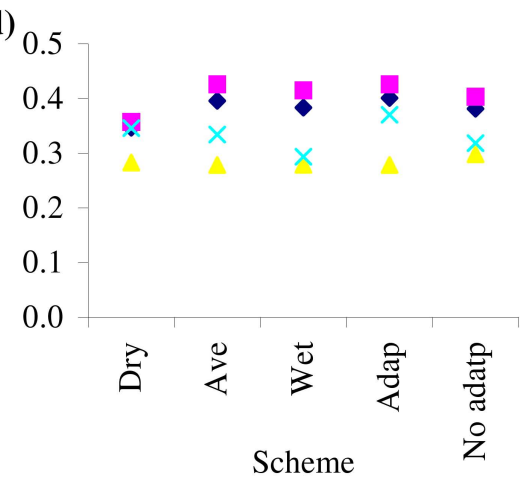

\section{HESSD}

8, 5891-5915, 2011

\section{Evaluation of the transferability of hydrological model}

S. Bastola et al.

\section{Title Page}

Abstract Introduction

Conclusions

References

Tables

Figures

14

4

Back

\section{Full Screen / Esc}

Printer-friendly Version

Interactive Discussion mance point for 1970s (dry decade) and 1980s (wet decade). Lower value indicates that the performances are near to the ideal performance point. 


\section{HESSD}

$8,5891-5915,2011$

\section{Evaluation of the transferability of hydrological model}
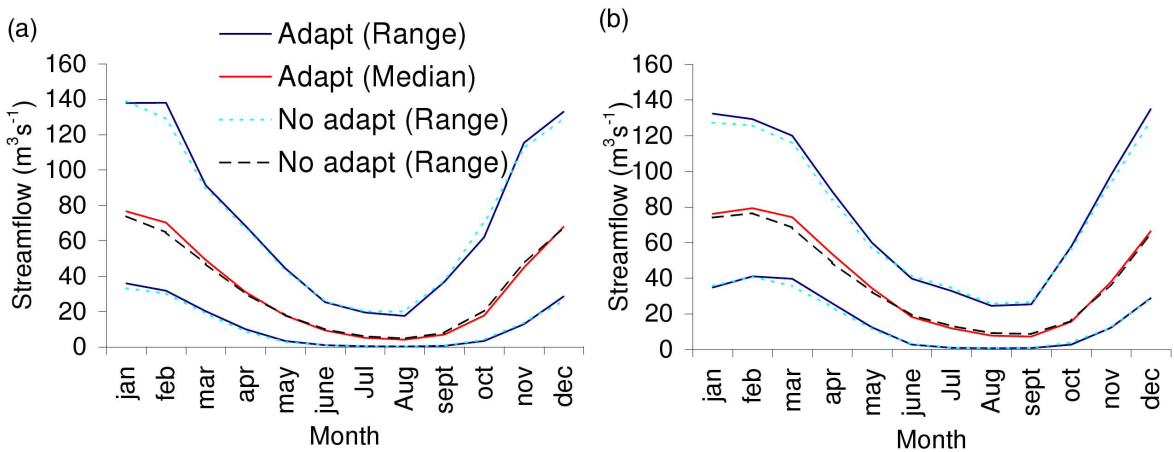

S. Bastola et al.

Fig. 9. Seasonal prediction intervals for the period from (2080s) 1971-2200 with and without adapting basin simulators ( $\mathbf{a}$ and $\mathbf{b}$ ) Boyne river basin, (c and $\mathbf{d}$ ) Moy river basin.

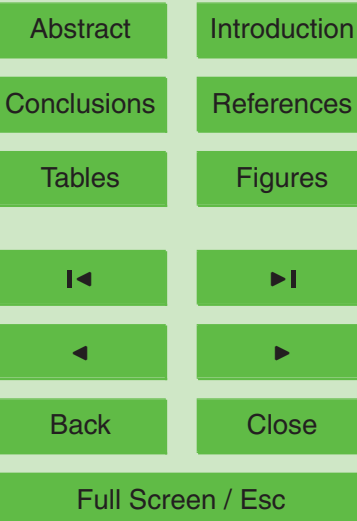

Printer-friendly Version

Interactive Discussion

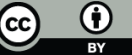

